\title{
UJI MUTU SEDIAAN CELUP DAUN BUNGA KERTAS (Bougainvillea glabra Choisy)
}

\author{
Charlis Palupi $^{1}$, Putri Sekar Ayu Nugraha ${ }^{2}$, Endang Ernawaningtyas ${ }^{3}$ \\ ${ }^{(1,2)}$ Akafarma Sunan Giri Ponorogo, Jl.Batoro Katong 32 Ponorogo \\ Email : ${ }^{1)}$ palupicharlis@gmail_com ${ }^{2)}$ putrisekaran@gamil_com \\ 3) endang.akafarma@gmail_com
}

\begin{abstract}
ABSTRAK
Latar Belakang: Tanaman bunga kertas memiliki banyak manfaat yang belum diketahui oleh masyarakat sehingga diperlukan cara untuk menginovasi daun bunga kertas agar dapat digunakan dalam kehidupan sehari-hari. Salah satu inovasi yaitu dengan membuat sediaan celup daun bunga kertas. Tujuan: Mengetahui mutu sediaan celup daun bunga kertas berdasarkan syarat mutu SNI 01-3753-2014. Metode: Sampel dalam penelitian yaitu sediaan celup daun bunga kertas dalam satu kali produksi, mengguakan teknik pengumpulan data Simple Random Sampling, kemudian dilakukan uji mutu terbatas pada uji organoleptik, uji kadar air, uji kadar abu larut dalam air terhadap abu total, uji kadar abu tidak larut asam, uji kealkalian abu larut dalam air, uji ALT, uji AKK. Hasil: Pengujian mutu SNI 01-3753-2014 bahwa sediaan celup daun bunga kertas memenuhi persyaratan. Hasil uji organoleptik air seduhan berwarna kuning kecoklatan, bau khas dan rasa khas, uji kadar air 4,9\%, uji kadar abu larut dalam air terhadap abu total 59,3\%, uji kadar abu tidak larut asam 0,6\%, uji kealkalian abu larut air 1,06\%, uji ALT 80,8 x $10^{1}$ koloni/gram, uji AKK 2,3 x $10^{1}$ koloni/gram. Simpulan: semua uji yang dilakukan memenuhi persyaratan mutu SNI 01-3753-2014.
\end{abstract}

Kata Kunci : sediaan celup daun bunga kertas, uji mutu.

\section{ABSTRACT}

Background: Paper flower plants have many benefits that are not yet known by the public, so we need a way to innovate paper flower leaves so that they can be used in everyday life. One of the innovations is to make paper flower leaf dye preparations. Objectives: To know the quality based on the quality requirements of SNI 01-3753-2014. Methods: The sample in the study was a paper flower leaf dye in one production, using simple random sampling data collection techniques, then carried out a limited quality test on organoleptic test, water content test, water soluble ash content test for total ash, insoluble ash content test. acid, alkaline water soluble ash test, ALT test, AKK test.. Result: Testing the quality of SNI 01-3753-2014 that the paper flower leaf dye meets the requirements except for the total ash content. Organoleptic test results of steeping water are brownish yellow, have a distinctive smell and taste, water content test is $4.9 \%$, water soluble ash content test for total ash is $59.3 \%$, ash content test is not soluble acid $0.6 \%$, alkaline water soluble ash test $1.06 \%$, ALT test $80.8 \times 10^{1}$ colonies / gram, AKK test $2.3 \times 10^{1}$ colonies / gram. Conclusions: All tests carried out meet the quality requirements of SNI 01-3753-2014.

Keywords: paper flower leaf preparation, quality test

\section{PENDAHULUAN}

Bunga kertas secara umum merupakan tanaman hias yang ditanam hampir di seluruh daerah tropis maupun subtropis. Tanaman ini memiliki family Nyctaginaceae. Kandungan senyawa berupa flavonoid, glikosida, fenol, alkaloid, saponin, steroid, tannin dan terpenoid (Ambasalu,2015). Keberadan tanaman bunga kertas di Kecamatan Jambon Ponorogo cukup melimpah namun tanaman bunga kertas ini kurang di manfaatkannya secara maksimal. Adapun khasiat atau manfaat dari tanaman bunga kertas 
Jurnal MEDFARM: Farmasi dan Kesehatan

Vol. 9, No.1, Januari 2020, hal 22-28

e-ISSN : 2715-9957

adalah bunga dan daun bunga kertas (Bougainvillea glabra) memiliki aktivitas antioksidan, antiinflamasi, antiulcer, antidiabetes, antidiarrhoeal, dan antimicroba (Abarca, 2018).

Salah satu manfaat dari daun bunga kertas dapat digunakan sebagai antidiarrhoeal sedangkan salah satu penyebab diare yaitu bakteri Escherichia-coli. Eschericichia-coli adalah salah satu bakteri gram negative yang hidup di dalam usus manusia bakteri ini tidak terlalu berbahaya namun pada saat tertentu menghasilkan racun dan menyebabkan diare akut. Obat tradisional merupakan salah satu warisan nenek moyang atau leluhur yang secara turun temurun digunakan dalam proses mencegah, mengurangi, menghilangkan atau menyembuhkan penyakit (Parwata,2016). Untuk penerapannya dari daun bunga kertas maka peneliti ingin membuat sediaan celup.Tujuan penelitian berdasarkan manfaat yang dimiliki maka dilakukan uji mutu berdasarkan SNI 01-3753-2014 untuk memudahkan proses pengaplikasian dalam masyarakat dalam memanfaatkan bahan alam.

\section{METODOLOGI PENELITIAN}

Penelitian ini dilaksanakan di Laboratorium Akafarma Sunan Giri Ponorogo. Sampel dalam penelitian yaitu sediaan celup daun bunga kertas dalam satu kali produksi, mengguakan teknik pengumpulan data Simple Random Sampling. Sampel kemudian dilakukan uji mutu SNI 01-3753-2014 terbatas pada uji organoleptik, uji kadar air, uji kadar abu larut dalam air terhadap abu total, uji kadar abu tidak larut dalam asam, uji kealkalian abu larut dalam air, uji ALT, dan uji AKK.

\section{Alat dan Bahan}

Alat timbang, Ayakan, Kertas timbang, Wadah, Talenan, Krus Porselen, Oven, Desikator, Nampan, Tanur, Pisau stainless, Kaca arloji, Lampu spirtus, Beaker glass, Pipet volume, Erlenmeyer, Cawan petri, Kapas, Jarum ose, Label, Kertas perkamen, Gelas ukur, cakram kertas, Tabung reaksi, Rak tabung, Penjepit.

Sampel "sediaan celup daun bunga kertas ", Aquadest, $\mathrm{AgNO}_{3}$, Indikator PP, $\mathrm{HCl} 10 \%, \mathrm{HCl} 0,1$ N, Alkohol 70\%, Media NA (Nutrient Agar), Media SGA (Sabouroud Glucose Agar), Formalin.

\section{Pembuatan sediaan celup daun bunga kertas}

Pembuatan sediaan celup daun bunga kertas ini diawali dengan pemetikan bahan baku segar daun bunga kertas $1 \mathrm{~kg}$ dari Kecamatan Jambon Ponorogo.Sortasi basah dilakukan untuk memisahkan kotorankotoran atau bahan-bahan asing lainnya dari daun bunga kertas dan dicuci dengan air mengalir. Proses penirisan dilakukan untuk menghilangkan sisa air dari proses pencucian.Proses pelayuan dilakukan dengan cara diangin-anginkan selama 3 jam untuk mengurangi kadar air. Daun bunga kertas yang sudah layu kemudian dilakukan proses pengeringan dengan menggunakan oven pada suhu $50^{\circ} \mathrm{C}$ selama 4 
Jurnal MEDFARM: Farmasi dan Kesehatan

Vol. 9, No.1, Januari 2020, hal 22-28

e-ISSN : 2715-9957

jam.Setelah daun bunga kertas kering kemudian diblender untuk mendapatkan kehalusan yang diinginkan. Serbuk daun bunga kertas yang sudah kering dimasukkan ke dalam kantong celup @ 3 gram perkantong.

\section{Uji organoleptik}

Pengamatan uji dengan indera penglihatan, penciuman, dan pengecap (lidah) yang dilakukan oleh panelis yang mempunyai kompetensi pengujian organoleptik (SNI,2014).

\section{Uji kadar air}

Prinsip kadar air adalah dengan menggunakan metode pemanasan biasa (gravimetric) adalah penguapan air yang terkandung dalam bahan dengan cara pemanasan, bahan tersebut dipanaskan sampai memiliki berat yang konstan. Berat yang konstan menunjukkan bahwa keadaan air pada bahan telah menguap seluruhnya, dan hanya tersisa berat kering bahan itu sendiri.

$$
\text { Perhitungan Kadar Air }=\frac{W_{1}-W_{2}}{W_{1}-W_{0}} \times 100 \%
$$

Keterangan :

$\mathrm{W}_{0}$ adalah bobot krus porselen kosong dan tutupnya, dinyatakan dalam gram

$\mathrm{W}_{1}$ adalah bobot krus dan contoh sebelum dikeringkan, dinyatakan dalam gram.

$\mathrm{W}_{2}$ adalah bobot krus dan contoh setelah dikeringkan, dinyatakan dalam gram.

\section{Uji kadar abu larut dalam air terhadap abu total}

Sampel yang digunakan adalah abu yang berasal dari penentuan kadar abu total (W). Tambahkan $20 \mathrm{ml}$ air suling kedalam cawan yang berisi abu total, panaskan sampai hampir mendidih dan saring dengan kertas saring. Kemudian bilas cawan dan kertas saring beserta isinya dengan air panas hingga jumlah filtrat kira-kira $60 \mathrm{ml}$. Simpan filtrat untuk penetapan alkalinitas abu larut dalam air. Pindahkan kertas saring dan isinya ke cawan semula, uapkan dengan hati-hati di atas penangas air. Abukan dalam tanur listrik pada suhu $(525 \pm 25)^{\circ} \mathrm{C}$. Pindahkan ke dalam desikator dan dinginkan selama 30 menit. Mengulangi hingga diperoleh bobot konstan (SNI, 2014).

$$
\text { Perhitungan }=\frac{W-W 3}{W} \times \frac{100}{100-K A} \times 100 \%
$$

Keterangan:

W adalah bobot hasil sampel dari penetapan abu total, dinyatakan dalam gram.

$\mathrm{W}_{3}$ adalah bobot abu tak larut air, dinyatakan dalam gram.

KA adalah kadar air, dinyatakan dalam \%. 


\section{Uji kadar abu tidak larut asam}

Sampel yang digunakan adalah abu tak larut dalam air. Tambahkan $25 \mathrm{ml} \mathrm{HCl} \mathrm{10 \%} \mathrm{ke} \mathrm{dalam}$ cawan yang berisi sampel. Dinginkan dan saring larutan menggunakan kertas saring. Bilas menggunakan air panas hingga air pencuci bebas asam. Hal ini dapat diuji dengan larutan AgNO3. Tempatkan kembali kertas saring dan isi ke dalam cawan, uapkan di atas penangas air yang mendidih, kemudian panaskan dalam tanur pada suhu $(525 \pm 25)^{\circ} \mathrm{C}$. Dinginkan ke dalam desikator selama 30 menit dan timbang. Ulangi pekerjaan sampai mencapai bobot yang tetap. Hitung kadar abu tak larut dalam asam (SNI, 2014).

$$
\text { Perhitungan }=\frac{\text { kadar abu }}{\text { abu larut air }} \times \frac{100}{100-K A} \times 100
$$

\section{Keterangan:}

KA adalah kadar air, dinyatakan dalam \%.

\section{Uji kealkalian abu larut dalam air}

Sampel yang digunakan adalah filtrat yang diperoleh dari penetapan kadar abu larut dalam air. Tempatkan filtrat dalam gelas piala kemudian titrasi dengan $\mathrm{HCl} 0,1 \mathrm{~N}$ menggunakan indikator PP. Sampai merah muda konstan (SNI, 2014).

$$
\text { Perhitungan }=\frac{V \times N \times 0,0561}{W} \times \frac{100}{100-K A} \times 100
$$

Keterangan:

$\mathrm{W}=$ Bobot sampel dari penetapan abu total, dinyatakan dalam gram.

$\mathrm{V}=$ Volume larutan yang diperlukan untuk titrasi contoh, dinyatakan dalam milimeter (ml).

$\mathrm{N}=$ Normalitas larutan $\mathrm{HCl}$.

$\mathrm{KA}=$ Kadar air, dinyatakan dalam \%.

\section{Uji ALT}

Metode yang digunakan dalam uji ALT yaitu, metode tuang (Pour Plate). Dari pengenceran yang dikehendaki, sebanyak $1 \mathrm{ml}$ atau $0,1 \mathrm{ml}$ larutan dipipet ke cawan petri steril kemudian dimasukkan media sebanyak 15-20 ml untuk menghindari kontaminasi luar selama penuangan media, cawan petri tidak boleh dibuka lebar. Setelah itu ratakan dengan hati-hati dengan gerakan melingkar. Setelah padat diinkubasi dengan suhu dan waktu yang sesuai. Kemudian hitung koloni yang didapat (Lay, 1994).

$$
\mathrm{ALT}=\frac{\Sigma C}{[(1 \times \mathrm{n} 1)+(0,1 \times \mathrm{n} 2) \times \mathrm{d}]}
$$

\section{Keterangan:}

$\mathrm{C}=$ Jumlah koloni dari tiap-tiap petri 
Vol. 9, No.1, Januari 2020, hal 22-28

e-ISSN : 2715-9957

$$
\begin{aligned}
& \mathrm{n}_{1}=\text { Jumlah petri dari pengenceran pertama yang dihitung } \\
& \mathrm{n}_{2}=\text { Jumlah petri dari pengenceran kedua } \\
& \mathrm{d}=\text { Pengenceran pertama yang dihitung. }
\end{aligned}
$$

\section{Uji AKK}

Metode yang digunakan dalam uji AKK yaitu metode tuang ( pour plate). Dari pengenceran yang dikehendaki, sebanyak $1 \mathrm{ml}$ atau $0,1 \mathrm{ml}$ larutan dipipet ke cawan petri steril kemudian dimasukkan media sebanyak 15-20 ml untuk menghindari kontaminasi luar selama penuangan media, cawan petri tidak boleh di buka lebar. Setelah itu ratakan dengan hati-hati dengan gerakan melingkar. Setelah padat diinkubasi dengan suhu dan waktu yang sesuai. Kemudian hitung koloni yang didapat (Lay, 1994).

Cara Perhitungan AKK

Pilih cawan petri dari satu pengenceran yang menunjukkan jumlah koloni antara 10 koloni - 150 koloni setiap cawan petri. Hitung semua koloni dalam cawan petri, kemudian hitung rata-rata jumlah koloni dan kalikan dengan faktor pengenceran. Nyatakan hasilnya sebagai jumlah kapang dan khamir per gram.

\section{HASIL DAN PEMBAHASAN}

\begin{tabular}{|c|c|c|c|c|}
\hline No. & Kriteria Uji & Satuan & Persyaratan & Hasil Uji \\
\hline \multirow[t]{5}{*}{1} & Keadaan Air seduhan & & & \\
\hline & Warna & - & Kecoklatan & Kuning \\
\hline & & & & kecoklatam \\
\hline & Bau & - & Khas & Khas \\
\hline & Rasa & - & Khas & Khas \\
\hline 2 & Kadar Air & $\%$ & Maks. 10 & 4,9 \\
\hline 3 & $\begin{array}{l}\text { Kadar abu larut dalam air } \\
\text { terhadap Abu total }\end{array}$ & $\%$ & Min. 45 & 59,3 \\
\hline 4 & $\begin{array}{l}\text { Kadar Abu Tidak Larut } \\
\text { Dalam Asam }\end{array}$ & $\%$ & Maks. 1,0 & 0,6 \\
\hline 5 & $\begin{array}{l}\text { Kealkalian Abu Larut Dalam } \\
\text { Air }\end{array}$ & $\%$ & $1,0-3,0$ & 1,06 \\
\hline \multirow[t]{2}{*}{6} & Cemaran Mikroba & & & \\
\hline & Angka Lempeng Total & Koloni/g & Maks. $3 \times 10^{3}$ & $80,8 \times 10^{1}$ \\
\hline
\end{tabular}

\section{Hasil uji sediaan celup daun bunga kertas}

Tabel 1. Hasil uji mutu 

Angka Kapang Khamir
Koloni/g
Maks. 5 x $10^{2}$
$2,3 \times 10^{1}$

Pada pengujian keadaan air seduhan sampel sediaan celup daun bunga kertas didapatkan hasil warna kuning kecoklatan, bau khas, dan rasa khas. Menurut SNI 01-3753-2014 keadaan air seduhan memiliki warna kuning kecoklatan, bau khas, rasa khas, sehingga dapat dinyatakan bahwa sampel sediaan celup daun bunga kertas memenuhi persyaratan yang sudah ditetapkan ditinjau dari uji organoleptis.

Pada pengujian sampel sediaan celup daun bunga kertas didapatkan hasil kadar air sebesar 4,9\%. Menurut SNI 01-3753-2014 batas kadar air pada sediaan celup daun bunga kertas yaitu kurang dari 10\%, sehingga dapat dinyatakan bahwa sampel sediaan celup daun bunga kertas memenuhi persyaratan. Pengujian kadar air bertujuan untuk mengetahui banyaknya air yang terkandung dalam zat atau banyaknya air yang terserap zat.

Pada pengujian sampel sediaan celup daun bunga kertas didapatkan hasil kadar abu larut dalam air sebesar 59,3\%. Menurut SNI 01-3753-2014 batas kadar abu larut dalam air pada sediaan celup daun bunga kertas yaitu minimal 45\%, sehingga dapat dinyatakan bahwa sampel sediaan celup daun bunga kertas memenuhi persyaratan. Pengujian kadar abu larut dalam air terhadap abu total bertujuan untuk mengetahui kandungan mineral yang terdapat dalam bahan tersebut maupun kontaminan selama proses pembuatan yang larut dalam air.

Pada pengujian sampel sediaan celup daun bunga kertas didapatkan hasil kadar abu tidak larut dalam asam sebesar 0,6\%. Menurut SNI 01-3753-2014 batas kadar abu tidak larut dalam asam pada sediaan celup daun bunga kertas yaitu maksimal 1,0\%, sehingga dapat dinyatakan bahwa sampel sediaan celup daun bunga kertas memenuhi persyaratan. Pengujian kadar abu tidak larut dalam asam bertujuan untuk mengetahui jumlah abu yang terdapat pada sisa komponen sisa anorganik atau mineral yang terdapat pada suatu bahan yang tidak larut dalam asam.

Pada pengujian sampel sediaan celup daun bunga kertas didapatkan hasil kealkalian abu larut dalam air sebesar 1,06\%. Menurut SNI 01-3753-2014 batas kadar kealkalian abu larut dalam air pada sediaan celup daun bunga kertas yaitu 1,0-3,0\%, sehingga dapat dinyatakan bahwa sampel sediaan celup daun bunga kertas memenuhi persyaratan. Pada pengujian kealkalian abu larut air bertujuan melihat kebasaan suatu sampel.

Pemeriksaan cemaran mikroba dengan Angka Lempeng Total memenuhi syarat SNI 01-35732014 apabila Angka Lempeng Total max $10^{3}$. Pada sampel sediaan celup daun bunga kertas diperoleh hasil $80.8 \times 10^{1} \mathrm{koloni} / \mathrm{gram}$ (808 koloni/gram). Sehingga dapat disimpulkan sampel memenuhi syarat ditinjau dari uji angka lempeng total. 
Vol. 9, No.1, Januari 2020, hal 22-28

e-ISSN : 2715-9957

Pemeriksaan cemaran mikroba dengan Angka Kapang Khamir memenuhi syarat SNI 01-35732014 apabila Angka Kapang Khamir max 10². Pada sampel sediaan celup daun bunga kertas diperoleh hasil 2,3 x $10^{1} \mathrm{koloni} / \mathrm{gram}$ (23 koloni/gram). Sehingga dapat disimpulkan sampel memenuhi syarat ditinjau dari uji angka kapang Khamir.

\section{KESIMPULAN}

Pengujian mutu SNI 01-3753-2014 bahwa sediaan celup daun bunga kertas memenuhi persyaratan.. Hasil uji organoleptik air seduhan berwarna kuning kecoklatan, bau khas dan rasa khas, uji kadar air 4,9\%, uji kadar abu larut dalam air terhadap abu total 59,3\%, uji kadar abu tidak larut asam 0,6\%, uji kealkalian abu larut air 1,06\%, uji ALT 80,8 x 10 koloni/gram, uji AKK 2,3 x $10^{1}$ koloni/gram.

\section{DAFTAR PUSTAKA}

Abarca-Vargas, R., \& Petricevich, V. L. (2018). Bougainvillea genus: A review on phytochemistry, pharmacology, and toxicology. Evidence-Based Complementary and Alternative Medicine.

Ambasalu, T. G., Ardana, M., \& Masruhim, M. A. (2015). Uji Aktivitas Antiinflamasi Ekstrak Etanol Bunga Bugenvil (Bougainvillea spectabilis) Terhadap Tikus Putih Galur Wistar. In Proceeding of Mulawarman Pharmaceuticals Conferences (Vol. 2, pp. 1-7).

Lay, W. 1994. Analisa Mikroba di Laboratorium. Jakarta: PT. Raja Grafindo Persada.

PARWATA, I. M. O. A. (2016). Obat Tradisional. http://simdos.unud.ac.id. Diakses pada, 26 april 2020.

Standar Nasional Indonesia. 2014. Teh Celup Nomor 3753:2014. Jakarta: Badan Standar Nasional. 